\title{
PENGARUH GAYA KEPEMIMPINAN CAMAT TERHADAP KINERJA PEGAWAI DI KANTOR KECAMATAN BUNGAYA KABUPATEN GOWA
}

\section{THE EFFECT OF SUBDISTRICT HEAD LEADERSHIP STYLE TO EMPLOYEES' PERFORMANCES AT THE BUNGAYA SUBDISTRICT OFFICE OF GOWA REGENCY.}

\author{
Muhammad Arifin Abd. Kadir \\ Program Studi Ilmu Administrasi, FISIP, Universitas Muhammadiyah Sorong \\ e-mail :alifnurarifin@yahoo.com
}

\begin{abstract}
Abstrak
Kepemimpinan berperan sangat penting dalam meningkatkan kinerjapegawai. Oleh karena itu penelitian ini bertujuan untuk mengetahui pengaruh gaya kepemimpinan Camat terhadap kinerja pegawai di Kantor Kecamatan Bungaya Kabupaten Gowa. Metode penelitian yang digunakan adalah deskriptif kuantitatif. Populasi adalah keseluruhan pegawai negeri sipil lingkup kantor Kecamatan Bungaya Kabupaten Gowa yang berjumlah 22 orang. Data dikumpulkan dari kuesioner, wawancara, dan telaah dokumen. Analisis data menggunakan uji validitas, uji realibilitas, uji normalitas, uji linieritas, uji hipotesis dan analisis regresi linier dengan bantuan SPSS. Hasil penelitian menunjukkan Gaya Instruksi berpengaruh positif dengan tingkat korelasi lemah namun tidak signifikan terhadap kinerja pegawai dengan nilai regresi yang menunjukkan angka positif sebesar 0,243 dan nilai signifikansi $0,276>0,05$. Gaya Konsultasi berpengaruh positif dengan tingkat korelasi sangat lemah dan tidak signifikan terhadap kinerja pegawai dengan nilai regresi yang menunjukkan angka positif sebesar 0,014 dan nilai signifikansi 0,951>0,05. Gaya Partisipasi berpengaruh positif dengan tingkat korelasi sangat lemah dan tidak signifikan terhadap kinerja pegawai dengan nilai regresi yang menunjukkan angka positif sebesar 0,069 dan nilai signifikansi $0,762>0,05$. Gaya Delegasi berpengaruh positif dengan tingkat korelasi kuat dan signifikan terhadap kinerja pegawai di Kantor Kecamatan Bungaya Kabupaten Gowa dengan nilai regresi yang menunjukkan angka positif sebesar 0,674 dan nilai signifikansi $0,001<0,05$ dimana setiap penambahan 1 gaya delegasi maka akan menambah 0,674 kinerja pegawai. Maka dari itu, Gaya Delegasi harus dipertahankan, dimana Camat memberi ruang kepada para pegawai agar bertanggung jawab sendiri akan tugas yang dibebankan kepadanya, hal ini dapat memicu kreativitas dari para pegawai.
\end{abstract}

Kata kunci: Gaya kepemimpinan, Kinerja pegawai, Kantor kecamatan. 


\begin{abstract}
Leadership is very important to upgrade employees' performance. Therefore, this study aims to determine the effect of subdistrict head leadership style to employees' performance at the Bungaya Subdistrict Office of Gowa Regency. The method used is descriptivequantitative. The population is all of the civil servants at the Bungaya Subdistrict Office of Gowa Regency, amounting to 22 employeses. Data were collected from questionnaires, interviews, and review of documents. The data is analyzed by taking validity test, realibilty test, normality test, linearity, hypothesis testing, and linear regression analysis with SPSS. The result showed a positive effect to the instruction style to the level of correlation is weak but not significant to employees' performances with a value of regression showed the positive numbers for 0,243 and significant value as 0,276>0,05. Consultation Style showed positive effect with the level of correlation is very weak and it is not significant to employess' performances with the value of regression showed positive number for 0,014 and significant value as 0,951 >0,05. Participation Style showed positive effect with the level of correlation is very weak and it is not significant to employess' performances with the value of regression showed positive number for 0,069 and significant value as 0,762 > 0,05. Delegation Style showed positive effect with the level of correlation is strong and significant to employees' performances with the value of regression showed positive number for 0,674 and significant value as 0,001 >0,05, it's mean that every additional 1 of the delegation style it will increase 0,674 the employees' performances. Therefore, Delegation Style should be maintained, where Subdistrict Head always give the space for employees to take responsibility about tasks assigned to them, this method can improve the creativity of employees.
\end{abstract}

Keywords: Leadership style, Employees' performances, Subdistrict office.

\title{
PENDAHULUAN
}

Kepemimpinan mempunyai peran yang sangat penting dalam meningkatkan kinerja pegawai karena kepemimpinan yang efektif memberikan pengarahan terhadap usaha-usaha semua pekerja dalam mencapai tujuan-tujuan organisasi. Gaya kepemimpinan yang efektif dibutuhkan pemimpin untuk dapat meningkatkan kinerja semua pegawai dalam mencapai tujuan organisasi sebagai instansi pelayanan publik. Dengan demikian, gaya kepemimpinan yang efektif diterapkan dalam birokrasi pemerintahan dalah gaya kepemimpinan yang selalu berusaha menyesuaikan dengan situasi dan kondisi, serta bersifat fleksibel dalam beradaptasi dengan kematangan bawahan dalamling kungankerjanya.

Pemimpin yang mampu beradaptif dalam perubahan apapun sebenarnya adalah pemimpin yang memiliki kompetens itinggi, memiliki sikap dan etos 
kerja professional dan antisipatif terhadap perubahan itu sendiri. Menurut Hersey \& Blanchard

(Pasolong,2013)

Kepemimpinan yang efektif diterapkan dalam memberikan pelayanan mencakup empat gaya kepemimpinan yaitu: Gaya Instruksi diterapkan kepada pegawai yang memilikitingkat kematangan yang rendah, yaitu pegawai yang tidak mampu dan tidak mau atau tidak yakin, untuk itu perintah harus jelas pula dalam menyampaikan cara pelaksanaanya. Gaya Konsultasi diterapkan kepada pegawai yang kematangan rendah menuju sedang, yaitu pegawai yang tidak mampu tapi mau, dikondisi ini pemimpin memberikan kesempatan untuk menyampaikan pendapat atau saran, dalam rangka perbaikan atau penyempurnaan keputusan.Gaya Partisipasi diterapkan kepada pegawai yang memiliki tingkat kematangan sedang menuju tinggi, yaitu pegawai yang mampu tetapi tidak mau atau kurang motivasi, memberikan kesempatan yang sama dalam berpartisipasi dalam melaksanakan kegiatan yang dijabarkan dari tugas-tugas pokok, sesuai dengan posisi/jabatan masing-masing. Gaya Delegasi diterapkan kepadapegawai yang memiliki tingkatkematangan yang tinggi, yaitu pegawai yang mampu dan mau melakukan pekerjaan. Pemimpin memberikan kesempatan yang sama dalam berpartisipasi dalam melaksanakan kegiatan yang dijabarkan dari tugas-tugas pokok, sesuai dengan posisi/jabatan masing-masing. Sedang penerima delegasi harus mampu memelihara kepercayaan itu, dengan melaksanakannya dengan penuh tanggung jawab.

Berdasarkan obervasi awal penulis di Kantor Kecamatan Bungaya menunjukkan adanya gejala menerapkan satu gaya kepemimpinan untuk semua jenis kematangan, yaitu gaya instruksi hal ini dapat dilihat dari perilaku pegawai yang tidak disiplin.

Contohnya seperti di gaya instruksi, dimana camat membuat keputusan dan memerintahkan pelaksanaanya saja. Seperti hanya memberii nstruksi tepa waktu masuk kantor tapi jika terlambat tanpa sanksi yang tegas diantara 12 pegawai kecamatan hanya sekitar 3 orang yang dating tepat waktu, yang lain dikarenakan sekitar 3 orang yang tinggal di kota Gowa dan1 orang di kota Makassar.

Gaya konsultasi, masih banyak komunikasi satu arah Cuma menanyakan kemudian menanggapi seadanya, seperti Kasi Trantib melaporkan pegawai yang datang terlambat.

Gaya partisipasi, kurangnya pegawai diberi kesempatan dalam kegiatan dari pimpinan sehingga membuat pegawai 
kurang berpartisipasi seperti di SK Nomor 11/SK/Pilbup/KPU.Kab.025.433280/V/20

15 Tentang Pembentukan Panitia Pemilihan Kecamatan (PPK) hanya melibatkan 2 orang saja.

Gaya delegasi, dimana Pimpinan mendelegasikan tugas sesuai tugas pokoknya tapi perintah pembuatan surat tugas terlambat sehingga pelaksanaanya dilakukan pegawai yang tinggal di Gowa atau Makassar seperti Surat Tugas Nomor : 050/76/Sek-Bungaya Tentang Forum Gabungan SKPD Kabupaten Gowa mendelegasikan kepada Kasi Perekonomian tapi yang menghadiri Staf Sekertariat.

Berdasarkan uraian dan permasalahan diatas terlihat bahwa gaya kepemimpinanyang melihat situasi dan kondisi memberikan dampak yang cukup berarti bagi riset dan juga dapat diterapkan dalambirokrasi.Dengan demikian peneliti tertarik untuk mengkaji lebih jauh mengenai penelitian ini. Maka dari itu penulis akan tertarik untuk mengkaji mengenai Pengaruh Gaya Kepemimpinan Camat Terhadap Kinerja Pegawai di Kantor Kecamatan Bungaya Kabupaten Gowa.

\section{METODE PENELITIAN}

Tipe Penelitian
Penelitian ini menggunakan jenis penelitian deskriptif kuantitatif dengan menggunakan data primer dan sekunder.Untuk mengamati bagaimana gaya kepemimpinan Camat di Kantor Kecamatan Bungaya Kab.Gowa. Metode survey dimaksud untuk melihat secara langsung latar belakang penelitian yang sangat relevan dengan penulisan ini, juga dianggap sangat objektif dan valid dalam rangka memahami dan memecahkan masalah.

\section{Populasi dan Sampel}

Populasi adalah keseluruhan pegawai negeri sipil lingkup Kecamatan Bungaya Kabupaten Gowa yang berjumlah 22 orang. Teknik sampling yang digunakan adalah sampling jenuh dimana semua anggota populasi yang ada pada pegawai lingkup Kecamatan Bungaya Kabupaten Gowa. Sampel ini digunakan karena jumlah populasi yang diambil untuk diteliti sangat sedikit.

\section{Teknik Pengumpulan Data}

Teknik pengumpulan data dalam penelitian ini adalah :

1. Penyebaran Kuesioner, dilakukan terhadap objek penelitian untuk menggali aspek-aspek yang relevan dan penting sebagai dasar analisis dan pembahasan yang akan dilakukan 
2. Wawancara, merupakan interaksi verbal yang dirancang untuk mendapatkan informasi melalui tanya jawab antara penelitian dengan informan.

3. Telaah dokumen, dilakukan untuk mengkaji dokumen-dokumen yang berkaitan dengan variabel penelitian dan fokus permasalahan dalam penelitian ini misalnya, peraturan perundang-undangan, kebijakankebijakan dan sumber data sekunder lainnya yang didapat dari dokumen.

\section{Instrumen Pengolahan Data}

Instrumen pnelitian yang digunakan adalah:

1. Angket yaitu daftar pertanyaan yang disampaikan kepada sejumlah responden yang akan dijadikan sampel

2. Pedoman wawancara yaitu pedoman yang dipakai dalam proses percakapan yang berbentuk tanya jawab dengan tatap muka langsung guna memperoleh informasi yang berkaitan dengan masalah penelitian.

3. Pedoman telaah dokumen yaitu pedoman yang dipakai sebagai panduan dalam melakukan proses kegiatan dalam memperoleh data sekunder (informasi) sehubungan dengan masalah yang diteliti.

\section{Teknik Pengolahan dan Analisis Data}

1. Teknik Pengolahan Data

Teknik pengolahan adalah data mentah yang dikumpulkan dari hasil kuesioner, wawancara, telaah dokumen yang akan diolah menjadi data kuantitatif dalam bentuk tabulasi.

2. Teknik Analisis Data mengunakan bantuan software SPSS.

a) Uji Instrumen Penelitian

1) Uji Validitas untuk mengukur sah atau valid tidaknya suatukuesioner.

2) Uji Realibilitas adalah pengukuran untuk suatu gejala. Semakin tinggi realibilitas suatu alat ukur, maka semakin stabil alat tersebut untuk digunakan. Tingkat realibilitas dapat dilihat dari hasil statistik Cronbach Alpha ( $\alpha)$. Suatu variabel dikatakan reliable jika memberikan nilai Cronbach Alpha $(\alpha)>0,60$.

b) Uji Asumsi Klasik

1) Uji Normalitas untuk mengetahui apakah populasi data berdistribusi normal atau tidak. Dalam penelitian digunakan uji One Sample KolmogorovSmirnov dengan menggunakan taraf signifikansi 0,05. Data dinyatakan berdistribusi normal 
jika signifikansi lebih besar dari $5 \%$ atau 0,05 .

2) Uji Linieritas untuk mengetahui apakah dua variabel mempunyai hubungan yang linear atau tidak secara signifikan. Pengujian pada SPSS dengan menggunakan Test for Linearity dengan taraf signifikansi 0,05. Dua variabel dikatakan mempunyai hubungan yang linear bila signifikansi (linearity) kurang dari 0,05 dan F hitung $<\mathrm{F}$ tabel.

3) Uji Hipotesis untuk mengetahui signifikansi pengaruh Gaya Kepemimpinan (x) terhadap Kinerja Pegawai (y) dengan teknik regresi linier sederhana dengan bantuan SPSS.

4) Analisis Regresi Linier Untuk menentukan ketepatan prediksi apakah ada kesesuaian/hubungan yang kuat antara variabel terikat (x) dengan variabel bebas (y), maka dalam penelitian ini digunakan rumus korelasi Spearman Rank dalam Sugiyono (2013), sebagai berikut:

$$
\rho=1-\frac{6 \sum \mathrm{b}_{1}^{2}}{n\left(n^{2}-1\right)}
$$

$\rho=$ koefisien korelasi Spearman Rank

HASIL PENELITIAN
Berdasarkan hasil olah data kuesioner yang diolah menjadi data kuantitatif dalam bentuk tabulasi untuk analisis Gaya kepemimpinan Camat Bungaya terhadap Kinerja Pegawai menunujukkan bahwa variabel gaya kepemimpinan yang terdiri dari 4 variabel yakni gaya instruksi, gaya konsultasi, gaya partisipasi dan gaya delegasi berada dalam kategori baik.

Dari hasil uji validitas menggunakan korelasi Bivariate Pearson (Produk Momen Pearson) dan Corrected ItemTotal Correlationdengan taraf signifikansi 0,05 dimana nilai $r$ tabel 0,432 menunjukkan bahwa semua item variabel Gaya Kepemimpinan dan Kinerja Pegawai valid dan dapat digunakan dalam tahap analisis.

Pengujian realibilitas dalam penelitian ini menggunakan teknik Alfa Cronbach. Pengujian dilakukan kepada 22 orang responden dengan jumlah pernyataan 33 item. Realibilitas instrument dapat diterima apabila memiliki koefisien realibilitas $>0,60$. Dari hasil perhitungan uji realibilitas diperoleh nilai Alfa Cronbach untuk semua variabel diatas dari 0,60 yang artinya alat pengumpulan data untuk semua variabel reliabel dan handal.

Pengujian normalitas didasarkan pada asumsi bahwa jika nilai signifikansi lebih besar dari 0,05 maka data 
berdistribusi normal. Berdasarkan hasil pengujian dengan Kolmogorov-Smirnov Test diperoleh nilai Kolmogorov-Smirnov $\mathrm{Z}$ sebesar 0,621 dan Asymp. Sig sebesar $0,828>0,05$ maka dapat disimpulkan bahwa data berdistribusi normal.

Sedangkan dalam uji linieritas dua variabel dikatakan mempunyai hubungan yang linear bila signifikansi (linearity) kurang dari 0,05 dan $F$ hitung $<F$ tabel. Pengujian pada SPSS dengan menggunakan Test of Linearity dengan taraf signifikansi 0,05. Berdasrkan tabel F dengan probabilitas 0,05 dimana nilai $F$ tabel $=4,35$ dari hasil itu, maka $\mathrm{F}_{\text {hitung }}=$ $0,788<\mathrm{F}$ tabel $=4,35$ dengan signifikansi $=0.000<0,05$, maka dapat disimpulkan bahwa antara variabel Gaya Kepemimpinan dengan Kinerja Pegawai mempunyai hubungan yang linier.

Selanjutnya pada uji Hipotesis dengan model persamaan regresi linier disajikan dalam tabel berikut:

Berdasarkan tabel Coefficients diatas, pada kolom B pada nilai konstan untuk variabel kinerja pegawai adalah sebesar 13.817 yang menjelaskan bahwa jika seluruh model dalam variabel independen (Gaya Kepemimpinan) tidak berpengaruh atau konstan terhadap variabel Kinerja Pegawai di Kantor Kecamatan Bungaya.
Setelah melakukan uji hipotesis selanjutnya dilakukan analisis korelasi untuk menjelaskan hubungan atau korelasi antar variabel, dan untuk mengetahui kontribusi masing-masing variabel terhadap variabel lainnya.

1. Pengaruh Gaya Instruksi terhadap Kinerja Pegawai

Hasil hitung SPSS diperoleh nilai korelasi gaya kepemimpinan instruksi terhadap kinerja pegawai pada Kantor kecamatan Bungaya Kabupaten Gowa yaitu 0,243 . Artinya terdapat pengaruh positif antara gaya kepemimpinan instruksi dengan kinerja pegawai dengan tingkat korelasi lemah.

Untuk hasil signifikansi gaya kepemimpinan Instruksi terhadap kinerja pegawai yaitu 0,276 artinya nilai signifikansi lebih besar dari 0,05 maka $\mathrm{H}_{0}$ diterima dan $\mathrm{H}_{1}$ ditolak, yang berarti tidak ada pengaruh secara signifikan antara gaya instruksi terhadap kinerja pegawai di Kantor Kecamatan Bungaya.

\section{Coefficients $^{\mathrm{a}}$}

\begin{tabular}{|c|c|c|c|c|c|}
\hline \multirow[b]{2}{*}{ Model } & \multicolumn{2}{|c|}{$\begin{array}{l}\text { Unstandardized } \\
\text { Coefficients }\end{array}$} & \multirow{2}{*}{$\begin{array}{c}\begin{array}{c}\text { Standardized } \\
\text { Coefficients }\end{array} \\
\text { Beta }\end{array}$} & \multirow[b]{2}{*}{$\mathrm{t}$} & \multirow[b]{2}{*}{ Sig. } \\
\hline & B & $\begin{array}{l}\text { Std. } \\
\text { Error }\end{array}$ & & & \\
\hline 1 (Constant) & 13.817 & 10.596 & & 1.304 & .210 \\
\hline Gaya_Instruksi & .435 & .445 & .205 & .978 & .342 \\
\hline Gaya_Konsultasi & -.069 & .431 & -.038 & -.160 & .875 \\
\hline Gaya_Partisipasi & -.263 & .366 & -.135 & -.719 & .482 \\
\hline Gaya_Delegasi & 1.679 & .377 & .722 & 4.458 & .000 \\
\hline
\end{tabular}

a. Dependent Variable:

Kinerja_Pegawai 
2. Pengaruh Gaya Konsultasi terhadap Kinerja Pegawai.

Hasil hitung SPSS diperoleh nilai korelasi gaya kepemimpinan Konsultasi terhadap kinerja pegawai pada Kantor kecamatan Bungayya Kabupaten Gowa yaitu 0,014. Artinya terdapat pengaruh positif antara gaya kepemimpinan konsultasi dengan kinerja pegawai dengan tingkat korelasi sangat lemah.

Untuk hasil signifikansi gaya kepemimpinan konsultasi terhadap kinerja pegawai yaitu 0,951 artinya nilai signifikansi lebih besar dari 0,05 maka $\mathrm{H}_{0}$ diterima dan $\mathrm{H}_{1}$ ditolak, yang berarti tidak ada pengaruh antara gaya konsultasi terhadap kinerja pegawai.

3. Pengaruh Gaya Partisipasi terhadap Kinerja Pegawai

Hasil hitung SPSS diperoleh nilai korelasi gaya kepemimpinan Partisipasi terhadap kinerja pegawai pada Kantor kecamatan Bungaya Kabupaten Gowa yaitu 0,069. Artinya terdapat pengaruh positif antara gaya kepemimpinan partisipasi dengan kinerja pegawai dengan tingkat korelasi sangat lemah.

Untuk hasil signifikansi gaya kepemimpinan partisipasi terhadap kinerja pegawai yaitu 0,762 artinya nilai signifikansi lebih besar dari 0,05 maka $\mathrm{H}_{0}$ diterima dan $\mathrm{H}_{1}$ ditolak, yang berarti tidak ada pengaruh antara gaya partisipasi terhadap kinerja pegawai.

\section{Pengaruh Gaya Delegasi terhadap Kinerja Pegawai}

Hasil hitung SPSS diperoleh nilai korelasi gaya kepemimpinan Delegasi terhadap kinerja pegawai pada Kantor kecamatan Bungaya Kabupaten Gowa yaitu $0,674 * *$. Artinya terdapat pengaruh positif antara gaya kepemimpinan delegasi dengan kinerja pegawai dengan tingkat korelasi yang kuat.

Untuk hasil signifikansi gaya kepemimpinan partisipasi terhadap kinerja pegawai yaitu 0,001 artinya nilai signifikansi lebih kecil dari 0,05 maka $\mathrm{H}_{1}$ diterima dan $\mathrm{H}_{0}$ ditolak, yang berarti ada pengaruh antara gaya delegasi terhadap kinerja pegawai, dimana setiap penambahan 1 gaya delegasi maka akan menambah 0,674 kinerja pegawai.

\section{PEMBAHASAN}

Dari hasil pengujian secara parsial (sendiri-sendiri) terhadap variabel gaya kepemimpinan menunjukan bahwa dari 4 indikator gaya kepemimpinan yaitu gaya instruksi, gaya konsultasi, gaya partisipasi, dan gaya delegasi. Hanya indikator gaya delegasi yang berpengaruh signifikan terhadap kinerja pegawai.

Semua gaya kepemimpinan berpengaruh atau berkorelasi secara positif 
terhadap kinerja pegawai, oleh karena itu gaya kepemimpinan yang tidak tepat akan menurunkan kinerja pegawai. Hal ini sejalan dengan pendapat Waldman dan Yammarino (1999), mengatakan bahwa gaya kepemimpinan akan mempengaruhi kinerja, namun dipengaruhi oleh situasi.

Dalam penelitian ini gaya kepemimpinan yang memberikan kontribusi yang besar terhadap peningkatan kinerja pegawai di kantor kecamatan Bungaya yakni gaya delegasi, yang artinya pegawai atau bawahan sudah cukup mampu memikul tanggung jawab. Dengan demikian gaya delegasi yang diterapkan oleh pimpinan dengan memberikan sedikit pengarahan atau dukungan memiliki kemungkinan efektif untuk meningkatkan kinerja pegawai. Hal ini dikarenakan bawahan diperkenankan untuk melaksanakan sendiri dan memutuskan sendiri pekerjaan yang dilakukannya sehingga memberikan ruang lebih untuk mampu bertanggung jawab sendiri pada segala keputusan atau ide yang diputuskan olehnya sendiri.

Hasil pengujian secara parsial (sendiri-sendiri) terhadap pengaruh gaya kepemimpinan delegasi terhadap kinerja pegawai menunjukkan bahwa terdapat pengaruh yang signifikan antara gaya kepemimpinan delegasi terhadap peningkatan kualitas kinerja pegawai.
Apabila pimpinan menerapkan gaya kepemimpinan tersebut maka akan meningkatkan kualitas kinerja pegawai, hal ini menunjukkan bahwa gaya kepemimpinan delegasi sangat baik diterapkan oleh Camat dibandingkan dengan menerapkan gaya instruksi, konsultasi, dan partisipasi. Hal ini dikarenakan pimpinan dalam hal ini Camat Bungaya Kabupaten Gowa lebih banyak melibatkan bawahan/pegawai untuk melaksanakan tugas sendiri yang sudah menjadi tanggung jawab masing-masing pegawai dengan sesekali memberikan arahan kepada para bawahannya.

Dalam hal ini gaya kepemimpinan delegasi di Kantor Kecamatan Bungaya mempunyai signifikansi terhadap kinerja pegawai dibandingkan dengan gaya kepemimpinan lain seperti gaya instruksi, gaya konsultasi dan gaya partisipasi yang sebenarnya sudah cukup baik dilakukan oleh Camat Bungaya. Kinerja pegawai yang merupakan hasil kerja secara kualitas maupun kuantitas dari tupoksi (tugas, pokok, dan fungsi) masing-masing. Hal ini sesuai dengan pendapat Mangkunegara (2007) yang menyatakan bahwa kinerja adalah hasil kerja secara kualitatif dan kuantitatif yang dicapai oleh seseorang pegawai dalam melaksanakan tugasnya sesuai dengan tanggung jawab yang telah diberikan kepadanya. 
Dari hal ini dapat kita lihat, jika kinerja merupakan prestasi atau pencapaian oleh pegawai/bawahan dalam melaksanakan tugas atau pekerjaannya sesuai dengan standar dan kriteria yang ditetapkan untuk pekerjaan itu dan sifatnya berkelanjutan maka dapat dikatakan bahwa pegawai di Kantor Kecamatan Bungaya sebenarnya sudah cukup baik mengenal tugasnya masing-masing dikarenakan pengalaman mereka selama bekerja di Kantor Kecamatan Bungaya dengan tugas pokok yang sebetulnya mereka sudah pahami betul standar prosedur kerja masing-masing tugas.

\section{KESIMPULAN DAN SARAN}

Hasil penelitian menunjukkan bahwa dari ke empat gaya kepemimpinan yakni Gaya Instruksi, Gaya Konsultasi, Gaya Partisipasi, dan Gaya Delegasi, menunjukan adanya pengaruh positif antara Gaya Kepemimpinan terhadap Kinerja Pegawai yang dibuktikan dengan nilai koefisien korelasi yang bernilai positif. Namun dalam hal signifikansi, hanya Gaya Delegasi yang signifikan terhadap Kinerja Pegawai yang dibuktikan dengan nilai signifikansi yang lebih kecil dari 0,05. Maka dari itu, Gaya Delegasi harus dipertahankan dan ditingkatkan, dimana Camat memberi ruang yang lebih luas kepada para pegawai atau bawahannya agar bertanggung jawab sendiri pada tugas yang dibebankan kepadanya, sehingga dalam hal ini dapat memicu kreativitas dari para pegawai.

\section{REFERENSI}

Aliem. 2015. Kecamatan Bungaya Dalam Angka Tahun 2015. Penerbit: Badan Pusat Statistik Kabupaten Gowa, Gowa, Sulawesi Selatan.

Mangkunegara, A.A.Anwar Prabu. 2007. Manajemen Sumber Daya Manusia Perusahaan. Salemba Infotek. Jakarta.

NawawiHadari,\& Martini Hadari. 1995.KepemimpinandanSupervisiPe ndidikan. BinaAksara, Jakarta.

Pasolong, Harbani. 2013. Kepemimpinan Birokrasi. Cetakan Ketiga. Penerbit Alfabeta, Bandung.

Rivai Veithzal, Prof.,Dr.M.BA, Deddy Mulyadi Prof., Dr., M.Si,. 2010. Kepemimpinan dan Perilaku Organisasi. Edisi ketiga, Cetakan ke 7. PT. Raja Grafindo Persada. Jakarta.

Sugiyono. 2013.

"MetodePenelitianAdministrasi”, Alf abetacv, Bandung.

Thoha,

Miftah. 2015.

KepemimpinanDalamManajemen.

Cetakan ke 18.

PT. GrafindoPersada, Jakarta. 
Waldman D.A dan Francis J. Yammarino. 1999. Leadership: Levels of Management and Levels of Analysis Effects. The Academy of Management Review. Vol. 24, No. 2 (Apr., 1999), pp.266-285. 